\title{
PKC $\alpha$ Mediates Maternal Touch Regulation of Growth-Related Gene Expression in Infant Rats
}

\author{
Saul M Schanberg*,', Vickie F Ingledue', Joanna Y Lee', Yusuf A Hannun ${ }^{2}$ and Jorge V Bartolome' \\ 'Department of Pharmacology and Cancer Biology, Duke University Medical Center, Durham, NC, USA; ${ }^{2}$ Department of Medicine, Duke \\ University Medical Center, Durham, NC, USA
}

\begin{abstract}
During short-term periods of separation of rat pups from their mothers, the loss of certain sensory signals suppresses the increase in ornithine decarboxylase (ODC) gene expression induced by the growth-promoting hormones prolactin (PRL) and growth hormone $(\mathrm{GH})$. Here, we identify a molecular mechanism through which maternal separation (MS) curtails ODC expression. Our results demonstrate that the absence of specific tactile stimuli provided by the mother limits PRL-evoked stimulation of ODC biosynthesis by interfering with sn-I,2-diacylglycerol's (DAG) ability to activate protein kinase C $\alpha$ (PKC $\alpha$ ) and consequently c-myc mRNA and max mRNA expression. The proteins encoded by these proto-oncogenes function as direct transactivators of the ODC gene. As ODC activity is obligatory for normal cell replication and differentiation, PKC $\alpha$ activation by DAG represents an important control point at which 'nurturing touch' regulates growth and development of the neonate. Such a mechanism can explain the maladaptive consequences of disrupting mother-infant tactile interactions as occurs in isolated premature babies. Also, it could provide a basis for developing therapeutic interventions to maximize growth potential in children failing-to-thrive despite normal maternal care.

Neuropsychopharmacology (2003) 28, I026-1030, advance online publication, 9 April 2003; doi:I 0. I038/sj.npp. I300I 25
\end{abstract}

Keywords: maternal touch; PKC $\alpha$; diacylglycerol; c-myc and max; neonatal development; ODC expression; Reactive Attachment Disorder of Infancy

\section{INTRODUCTION}

Survival of the mammalian neonate is highly dependent on its ability to process sensory information continuously and adapt to changing ambient conditions by expressing appropriate behavior and supportive physiology. Since the mother normally comprises the prime source of environmental input, she essentially determines the infant's psychobiological state. Our laboratory has shown that during short-term periods of maternal separation (MS), the loss of certain sensory signals provided by the mother initiates in the infant a shift from a growth-supportive strategy to one of energy conservation until contact with the mother is re-established. More specifically, MS triggers a coordinated pattern of responses in preweanling rat pups ( $<20$ days old) that includes: (1) a decrease in ornithine decarboxylase (ODC) basal levels in major organs, (2) a suppression of tissue ODC responsiveness to administered prolactin (PRL) and growth hormone (GH), (3) an

*Correspondence: Dr SM Schanberg, Department of Pharmacology and Cancer Biology, Duke University Medical Center, Box 3813, Durham, NC 27710, USA, Tel: + 9196845187,

E-mail: schan003@mc.duke.edu

Received 03 August 200I; revised 28 September 200I; accepted 26 November 2002

Online publication: 17 December 2002 at http://www.acnp.org/ citations/Npp 121702440 inhibition of GH secretion (Butler et al, 1978; Kuhn et al, 1979; Evoniuk et al, 1979; Schanberg et al, 1984; Pauk et al, 1986; Wang et al, 1996), and (4) a decrease in DNA synthesis (Greer et al, 1991). Further experiments established that this unique biological adaptation to MS is not related to nutritional deprivation or alterations in body temperature, but instead results from the absence of specific tactile stimuli as all effects of MS are prevented or reversed by stroking the pups with a brush simulating normal maternal licking behavior (Evoniuk et al, 1979; Schanberg et al, 1984; Pauk et al, 1986).

Interestingly, the pattern of responses in neonatal rats separated from their dam is strikingly similar to that observed in nonorganic failure-to-thrive children (now classified Reactive Attachment Disorder of Infancy; RADI) and in hospitalized preterm human neonates. As in the rat pup model of MS, children with RADI exhibit slow growth rates, diminished secretion of $\mathrm{GH}$, and impaired responsiveness to administered GH (Powell et al, 1967a, b; Frasier and Rallison, 1972). In turn, we found that premature babies given supplemental tactile stimulation while hospitalized showed greater weight gain (Field et al, 1986, Scafidi et al, 1990), enhanced behavior, and more mature sympathoadrenal function (Kuhn et al, 1991), as compared to control groups who received standard nursery care but no additional tactile stimuli. Supplemental tactile stimulation not only proved beneficial for high-risk preterm babies, 
but also for full-term babies born to depressed mothers (Field et al, 1996). These studies in animals and humans indicate that 'nurturing touch' is a prerequisite for normal mammalian growth and development.

The similarities between the MS syndrome in rat pups and human babies suggest a common etiology. Hence, identifying the underlying mechanisms by which maternalinfant interactions optimize growth potential in the neonate is of import to advance our understanding of the basic principles governing normal mammalian development.

\section{METHODS}

\section{Animal Treatments}

Lactating CD female rats with 6-day-old litters (10 pups per litter) were obtained from Charles River Laboratories (Raleigh, NC) housed in breeding cages in a vivarium maintained at $22^{\circ} \mathrm{C}$ with a 12 -h light-dark cycle, and provided food (Purina Lab Chow, Ralston-Purina, St Louis, MO) and water ad libitum. At 9 days of age (the day before experimentation) animals were randomized and transferred from the vivarium to the laboratory. Finally, to minimize differences in maternal care provided by individual dams, pups from all experimental groups designated not to be maternally deprived were assigned to each dam. All animals were killed at the same time of the day to minimize circadian influences on the parameters under investigation.

\section{ODC Activity}

Livers were quickly dissected, blotted, weighed, homogenized (Polytron) in $19 \mathrm{vol}$ (wt: vol) of ice-cold $10 \mathrm{mM}$ Tris$\mathrm{HCl}(\mathrm{pH} 7.2)$, and ODC activity was determined in the $28000 \mathrm{~g}$ for $20 \mathrm{~min}$ supernatant as previously reported (Slotkin and Bartolome, 1986). Essentially, the incubation medium contained $0.9 \mathrm{ml}$ of supernatant and final concentrations of $50 \mu \mathrm{M}$ pyridoxal-5'-phosphate, $1.8 \mathrm{mM}$ dithiothreitol and $4.8 \mu \mathrm{M} \mathrm{L}-\left[1-{ }^{14} \mathrm{C}\right]$ ornithine $(58.0 \mathrm{mCi} / \mathrm{mmol}$; New England Nuclear Corp., Boston, MA) in a total volume of $1 \mathrm{ml}$. Vials were capped with serum stoppers (into which plastic center wells containing paper filter wicks were suspended) and incubated for $30 \mathrm{~min}$ at $37^{\circ} \mathrm{C}$. The reaction was stopped with $0.5 \mathrm{ml}$ of $10 \%$ trichloroacetic acid, and the ${ }^{14} \mathrm{CO}_{2}$ evolved was trapped with $0.2 \mathrm{ml}$ of hyamine hydroxide (injected onto the paper wicks) during a second 30-min incubation. Center wells were removed, placed in scintillation fluid and counted for radioactivity. ODC activity is expressed as nmols of ${ }^{14} \mathrm{CO}_{2}$ evolved/g of tissue wt per h.

\section{Poly(A) ${ }^{+}$RNA Isolation and Northern Blot Analysis}

Total liver RNA was extracted with acid guanidinium thiocyanate-phenol-chloroform (Chomczynski and Sacchi, 1987), enriched for poly (A) ${ }^{+}$RNA by Oligotex-dT chromatography (Qiagen Inc., Santa Clarita, CA), and analyzed for $c-m y c$ and ODC mRNAs as previously reported (Wang et al, 1996). The ODC probe consisted of a $2.2-\mathrm{kb}$ EcoR1 fragment of mouse ODC (obtained from $\operatorname{Dr} \mathrm{P}$ Blackshear, Duke University, Durham, NC), while the c-myc probe was a $4.8-\mathrm{kb} \mathrm{Xbal}-\mathrm{BamH} 1$ fragment of mouse $c-m y c$ gene containing the second and third exons (provided by Dr $\mathrm{R}$ Weinberg, MIT, Cambridge, MA). Probes were radiolabeled with $5^{\prime}-\left[\alpha_{-}{ }^{32} \mathrm{P}\right] \mathrm{dCTP}(3000 \mathrm{Ci} / \mathrm{mmol}$; New England Nuclear, Boston, MA) to a specific activity of 1 to $2 \times 10^{6} \mathrm{cpm} / \mu \mathrm{g}$, using a Primed-It Random Primer DNA Labeling kit (Stratagene, La Jolla, CA) and NucTrap push columns to separate nonincorporated deoxyribonucleoside triphosphates from the radiolabeled probes.

\section{Protein Kinase C (PKC) Activity}

PKC activation in vivo was assessed by adapting an immunoprecipitation procedure developed by Lee et al (1996). Livers were homogenized (Polytron) in 10 volumes of cold $50 \mathrm{mM}$ Tris- $\mathrm{HCl}$ ( $\mathrm{pH} \mathrm{7.4)} \mathrm{containing} 25 \mathrm{mM} \mathrm{KCl}$, $250 \mathrm{mM}$ sucrose, $0.5 \mathrm{mM}$ EDTA, $10 \mu \mathrm{g} / \mathrm{ml}$ leupeptin, $10 \mu \mathrm{g} / \mathrm{ml}$ aprotinin, $10 \mu \mathrm{g} / \mathrm{ml}$ trypsin-chymotrypsin inhibitor, $5 \mu \mathrm{g} / \mathrm{ml}$ pepstatin $\mathrm{A}$, and $1 \mathrm{mM}$ phenylmethylsulfonyl fluoride. The homogenates were cleared by filtering through several layers of cheesecloth, incubated with $\alpha$ or $\delta$ PKC antibodies for $60 \mathrm{~min}$ at $4{ }^{\circ} \mathrm{C}$, and the immunoprecipitates were collected by adsorption to protein A-Sepharose beads. Immunocomplexes bound to protein A-Sepharose beads were washed three times with washing buffer $(0.5 \%$ Nonidet P-40, 0.5\% deoxycholate in cold PBS), two times with kinase buffer (10 mM NaF, $1 \mathrm{mM} \mathrm{Na} \mathrm{VO}_{4}, 0.5 \mathrm{mM}$ EDTA, $0.5 \mathrm{mM}$ EGTA, $2 \mathrm{mM} \mathrm{MgCl}_{2}, 10 \mu \mathrm{g} / \mathrm{ml}$ leupeptin, $10 \mu \mathrm{g} / \mathrm{ml}$ aprotinin, $10 \mu \mathrm{g} / \mathrm{ml}$ trypsin-chymotrypsin inhibitor, $1 \mathrm{mM}$ phenylmethylsulfonyl fluoride in $50 \mathrm{mM}$ Tris- $\mathrm{HCl}(\mathrm{pH} \mathrm{7.4)})$, and then assayed for PKC activity (in the absence or presence of calcium and the lipid activators phosphatidylserine (PS) and dioleoylglycerol (DON)) using histone $\mathrm{H}_{3}$ as an exogenous substrate.

\section{Statistical Analysis}

Data were analyzed using one- or two-way analysis of variance (ANOVA), followed by Student-Newman-Keuls test for pairwise multiple comparisons. Statistical significance was accepted at $P<0.05$.

\section{RESULTS AND DISCUSSION}

As noted earlier, in rat pups, one of the salient characteristics of the MS syndrome is the suppression of PRL- and $\mathrm{GH}$-induced stimulation of ODC activity, a rate-limiting enzyme in the biosynthesis of the polyamines spermidine and spermine (Pegg and Williams-Ashman, 1968), key regulators of cell growth, multiplication, and differentiation (Pegg and McCann, 1982; Heby, 1981; Slotkin and Bartolome, 1986). Although details of the molecular processes mediating ODC induction by trophic hormones are still unclear, strong evidence indicates a major role for the signaling enzyme PKC. Indeed, upregulation of ODC activity was one of the first cellular events to be associated with PKC function (Jetten et al, 1985). Specifically, PRL and GH appear to increase hepatic ODC activity by stimulating the hydrolysis of phosphatidylinositol 4,5-bisphosphate (PIP2) to sn-1,2-diacylglycerol (DAG) (Jetten et al, 1985; Buckley and Buckley, 1991), a physiologic activator of PKC (Nishizuka, 1988). Furthermore, PKC activation via receptor-mediated phosphoinositide turnover heightens $c$-myc 


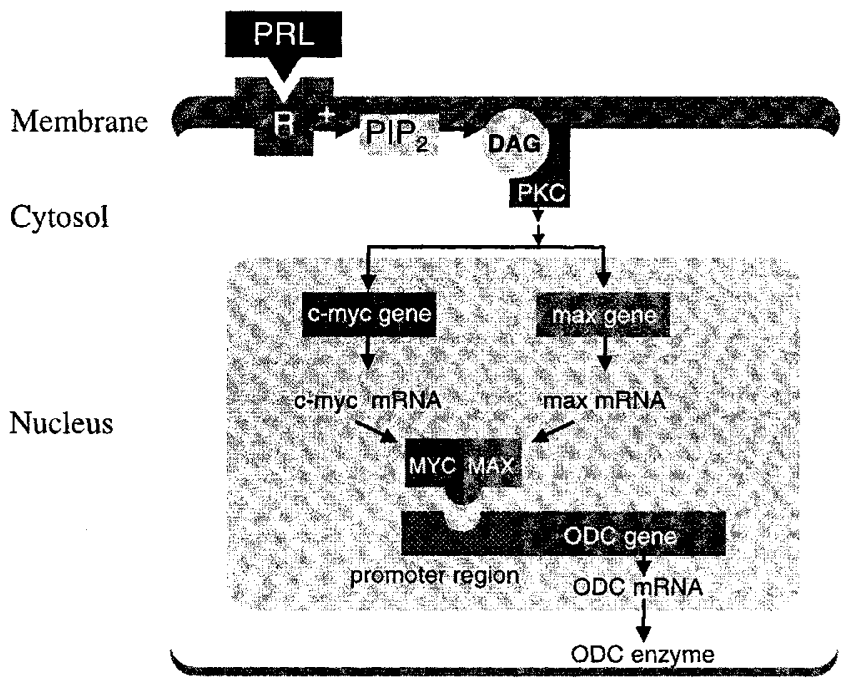

Figure I Schematic representation of the signal-transduction pathway mediating PRL induction of ODC enzyme activity.

expression (Rozengurt and Sinnett-Smith, 1987), a protooncogene thought to act physiologically as a regulator of ODC gene transcription (Bello-Fernandez et al, 1993; Peña et al, 1993). In this context, we have obtained evidence implicating $c-m y c$ and the related proto-oncogene max in the inhibition by MS of PRL-evoked increases in ODC activity (Wang et al, 1996). Collectively, these findings raised the possibility that MS suppressed PRL's ability to stimulate ODC activity by interfering with a signaltransduction pathway involving DAG, PKC, and $c-m y c l$ $\max$ (Figure 1). The current studies describe a series of experiments designed to test this hypothesis.

First, we evaluated the ability of sn-1,2-dioctanoylglycerol (diC8; Avanti Polar Lipids, Alabaster, AL) to increase ODC activity in the liver of rat pups kept with their mother throughout the experiment. DiC8 is a synthetic, long-acting, cell permeable DAG analog that has been reported to enhance both PKC and ODC activity in cultured cells (Jetten et al, 1985). As shown in Figure 2a, ODC values in animals administered diC8 were markedly higher than those obtained in pups treated with vehicle (DMSO: saline; $2: 1$ ). These results established that this DAG analog is capable of increasing ODC activity in vivo. More importantly, it verified that the upregulation of ODC by PRL could be mimicked by diC8. In the light of these results, we investigated the effect of MS on hepatic ODC response to diC8. For this purpose, we separated a group of pups from their mothers for $2 \mathrm{~h}$, injected them with diC8 or vehicle, and measured ODC levels $4 \mathrm{~h}$ later. As was the case for PRL, MS-suppressed diC8-induced stimulation of ODC activity (Figure 2b). The evidence obtained suggests that MS downregulates tissue ODC responses to $\mathrm{diC} 8$, and presumably to PRL, by 'uncoupling' the signaling conduit at a locus downstream of DAG. This idea is in accord with earlier observations by our laboratory indicating that MS acts at a postreceptor intracellular site to inhibit ODC induction by trophic hormones (Schanberg et al, 1984).

To ensure that the inability of diC8 to induce ODC gene expression during MS is indeed caused by the absence of active mothering behavior, separate studies were performed in animals placed with urethane-anesthetized lactating

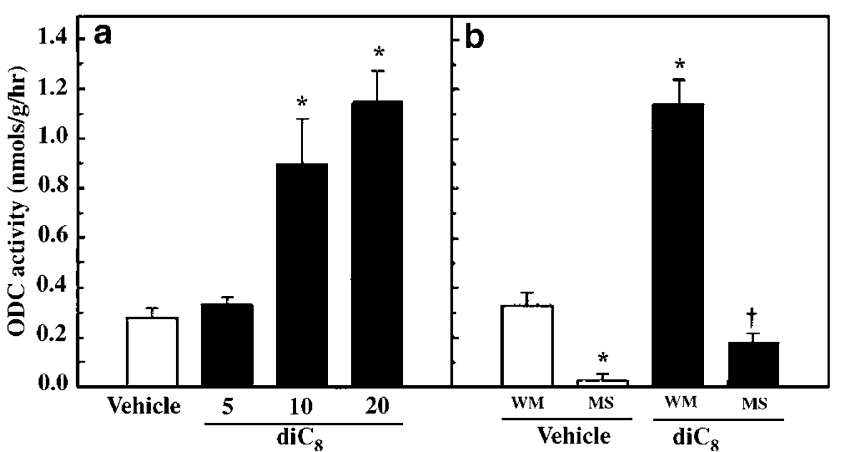

Figure 2 (a) Dose-response effects of diC8 on hepatic ODC activity in 10 -day-old rat pups with lactating mothers. Animals (5-12 per group) were administered diC 8 at the doses indicated above (nmols/g body wt, i.p.) or vehicle (DMSO: saline, 2: I), and livers were assayed for ODC activity $4 \mathrm{~h}$ after injection. $* P<0.05$ vs vehicle group. (b) Effect of MS on diC8-induced stimulation of hepatic ODC activity. Pups with lactating mothers (WM) or maternally separated (MS) for $2 \mathrm{~h}$ were administered diC8 $(20 \mathrm{nmols} / \mathrm{g}$ body wt, i.p.), and returned to their experimental group. After $4 \mathrm{~h}$, livers ( I I-24 per group) were analyzed for ODC activity. $* P<0.05$ vs vehicleWM group, ${ }^{\dagger} P<0.05$ vs diC $8-W M$ group.

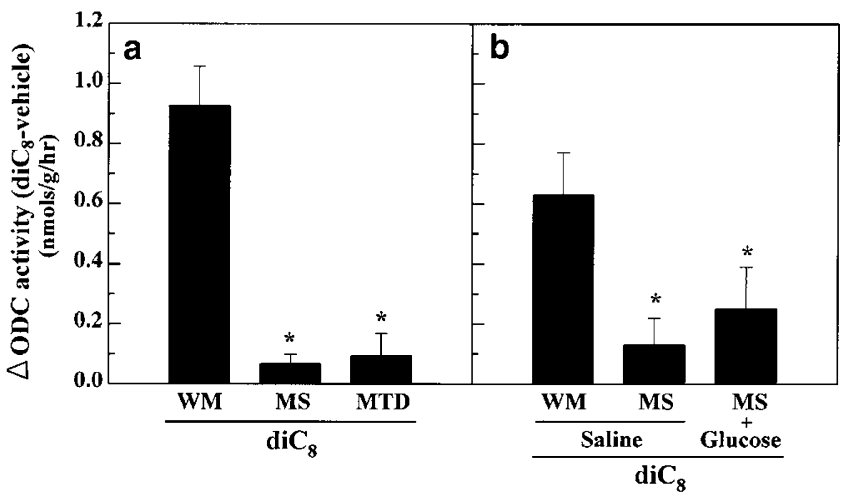

Figure 3 Effect of maternal tactile deprivation (MTD) on diC8-induced stimulation of hepatic ODC activity. Pups with lactating mothers (WM), maternally separated (MS) for $2 \mathrm{~h}$, or touched deprived (left with an anesthetized lactating female) were administered dic8 $(20 \mathrm{nmols} / \mathrm{g}$ body $w t)$ or vehicle, and returned to their experimental group. After $4 \mathrm{~h}$, livers were assayed for ODC activity. Baseline values were: $0.228 \pm 0.037$ (vehicle-WM), $0.028 \pm 0.002$ (vehicle-MS), and $0.120 \pm 0.041$ (vehicleMTD). ${ }^{*} P<0.05$ vs diC $8-W M$ group.

female rats. Such a treatment does not affect milk production/ejection or pup's suckling behavior (Lincoln et al, 1973; Butler et al, 1978). Under these conditions, all passive sensory stimuli provided by the mother and home nest environment are maintained; pups are in constant physical contact with her and suckle normally, but obviously they are not licked. As shown in Figure 3, diC8induced stimulation of ODC activity in pups with anesthetized dams was significantly less than that observed in pups with an actively nurturing mother. The effect cannot be attributed to the anesthetic crossing from the dam to the pup through the milk, as urethane given to the pup directly does not interfere with ODC induction (Kuhn et al, 1979).

Recently, we have shown that the inhibition by MS of PRL-evoked increases in ODC activity correlates with a reduced expression of $c-m y c$ and max mRNA (Wang et al, 1996). The proteins myc and max are thought to be involved 
intimately in the regulation of ODC gene expression and in mitogenic responses to ligands that act through PKC signaling cascades (Rozengurt and Sinnett-Smith, 1987; Bello-Fernandez et al, 1993; Peña et al, 1993). These observations are consonant with the notion that the loss of ODC response to PRL during MS may ultimately reflect PRL's failure to induce $c-m y c$ gene expression. If so, diC8 like PRL would normally be expected to increase $c-m y c$ and ODC mRNA levels, and that MS would block this effect. As predicted, diC8 administration markedly increased hepatic accumulation of both gene transcripts in control but not in MS pups (Figure 4). These results are particularly important as they indicate that MS blocks diC8 stimulation of ODC activity by acting at a site after DAG formation and prior to ODC gene transcription. Also, they are in accord with the literature in that an overproduction of $c-m y c$ mRNA has a positive impact on ODC gene expression (Bello-Fernandez et al, 1993; Peña et al, 1993). In turn, contrary to the

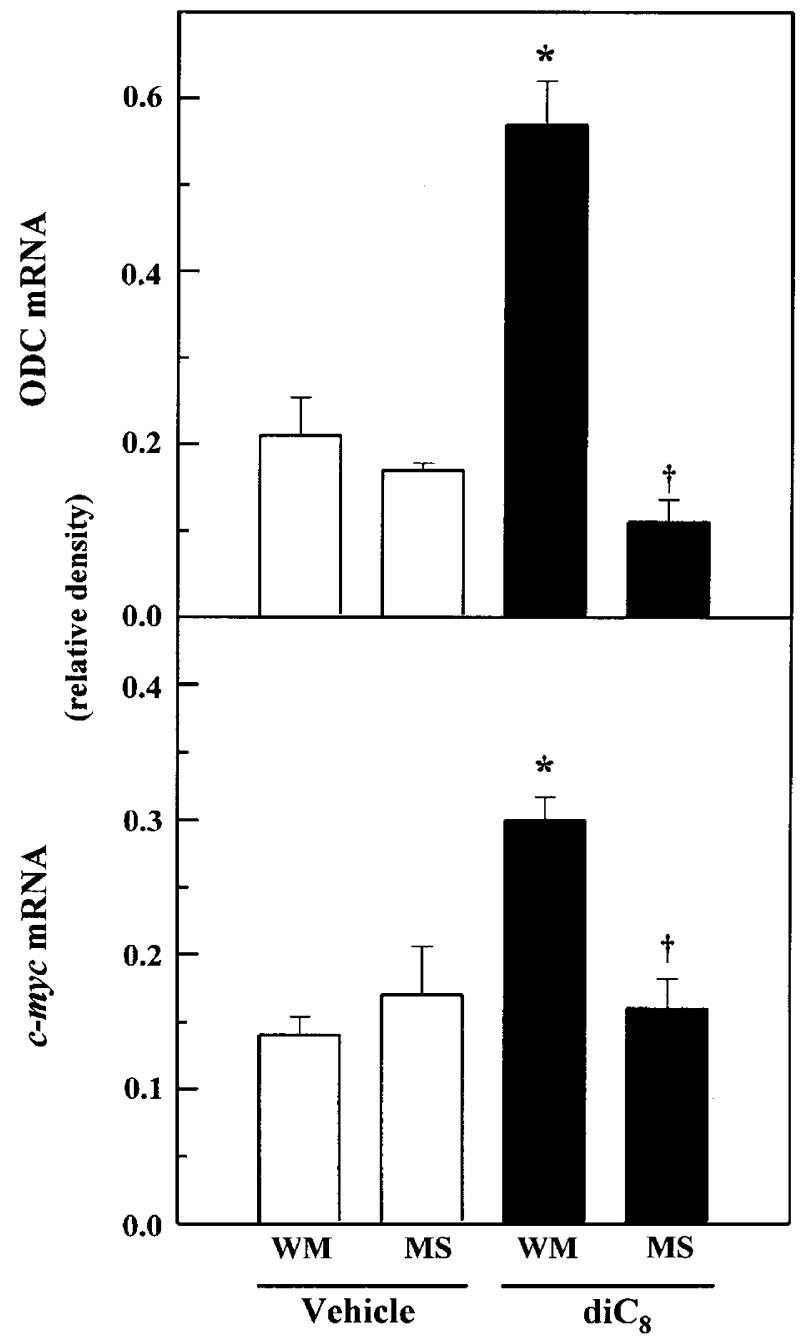

Figure 4 Effects of MS on dic8-induced stimulation of hepatic c-myc and ODC mRNA expression. Pups with lactating mothers (WM) or maternally separated (MS) for $2 \mathrm{~h}$ were administered diC8 (20 nmols/g body $\mathrm{wt})$ or vehicle, and returned to their experimental group. After $2 \mathrm{~h}$, livers were analyzed for c-myc and ODC mRNA levels. Data represent the densitometric analysis of Northern blot autoradiograms of two separate experiments. ${ }^{*} P<0.05$ vs respective $W M-V$ ehicle groups, ${ }^{\dagger} P<0.05$ vs respective WM-diC8 groups. suppression of diC8-evoked accumulation of $c-m y c$ and ODC mRNA levels, MS did not alter $c-m y c$ or ODC mRNA values in pups injected with vehicle instead of diC8 (Figure 4). This finding supports our earlier studies indicating that, in developing rat tissues, the molecular mechanisms regulating basal (unstimulated) ODC activity are distinctly different from those influencing stimulated ODC activity (Bartolome et al, 1995).

Finally, to establish further PKC as a prime mediator of the MS syndrome we investigated the effect of MS on changes in hepatic PKC activity evoked by PRL. It is now recognized that PKC consists of a family of isoenzymes exhibiting individual biological functions and distinct patterns of tissue distribution (Nishizuka, 1988). We targeted the $\alpha$ and $\delta$ isoforms because of their predominance in the liver (Alessenko et al, 1992). Figure 5a demonstrates the calcium and lipid dependency of PKC $\alpha$ in the assay (Nishizuka, 1988). Consistent with the lack of effect on $c-m y c$ and ODC mRNA levels in animals injected with saline, MS did not alter the PKC $\alpha$ activity in this experimental group of animals (Figure $5 \mathrm{~b}$ ). This appears to rule out the participation of PKC $\alpha$ in MS-induced decreases
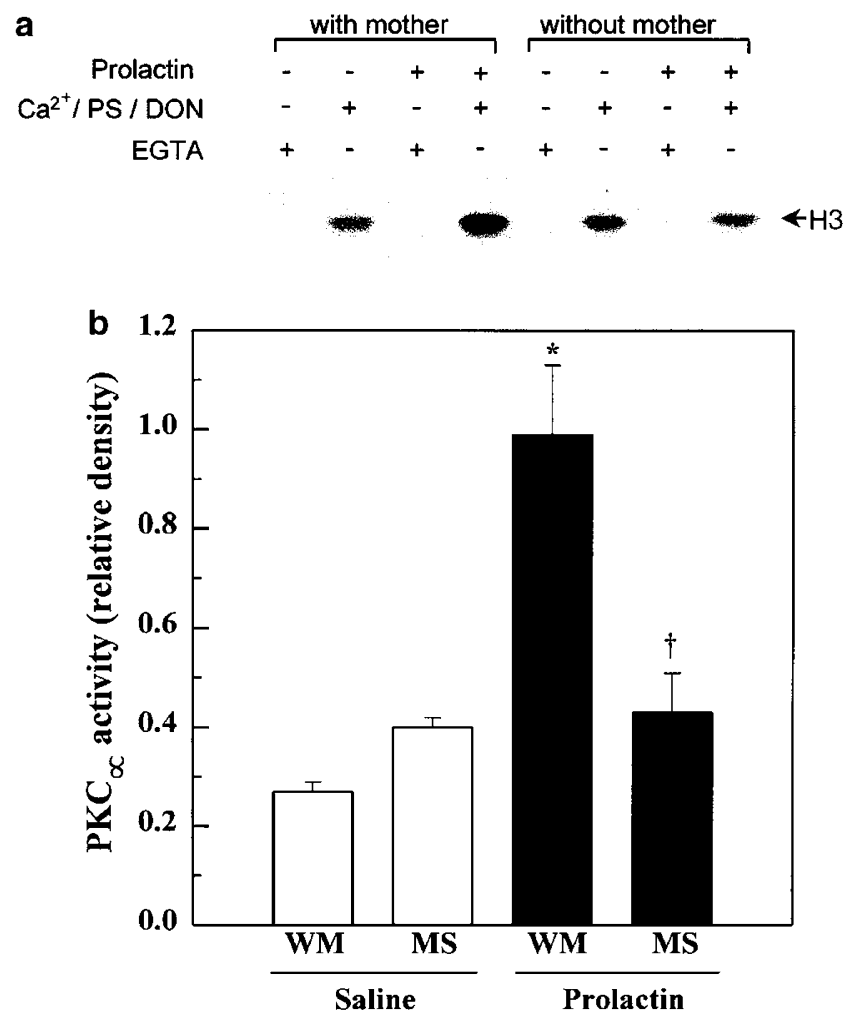

Figure 5 Effect of MS on PRL-induced stimulation of hepatic PKC $\alpha$ activity. Pups with lactating mothers (WM) or maternally separated for $2 \mathrm{~h}$ were administered PRL (20 mg/kg, i.p., Sigma, St Louis, MO), and returned to their experimental group. After 30 min, livers were analyzed for PKC $\alpha$ activity. (a) Basal PKC $\alpha$ activity was defined in the presence of $10 \mathrm{mM}$ EGTA. Stimulated PKC $\alpha$ activity was determined in the presence of $\mathrm{Ca}^{2+}$ $(1.2 \mathrm{mM})$ and its lipid activators phosphatidylserine (PS; $1.2 \mathrm{mM})$ and dioleoylglycerol (DON; $3.3 \mu \mathrm{M}$ ), using histone as the exogenous substrate. Proteins were separated by SDS-PAGE on a 10\% gel, and kinase activity evaluated by autoradiography. Results represent two separate experiments. Histone phosphorylation is indicated by an arrow on the right. (b) Densitometric analysis of autoradiograms. $* P<0.05$ vs respective WMvehicle groups, ${ }^{\dagger} P<0.05$ vs respective MS-vehicle groups. 
in basal ODC levels. In contrast, PRL markedly increased the hepatic PKC $\alpha$ activity in control pups but not in those subjected to MS (Figure 5b). Clearly, MS severely curtails PRL's ability to activate PKC $\alpha$. Interestingly, the effect was specific for $\mathrm{PKC} \alpha$, as no significant changes in $\mathrm{PKC} \delta$ levels were observed (data not shown). Thus, it is highly likely that the diminished ODC gene response to diC8 during MS, and therefore to PRL, is the result of an impaired activation of $\mathrm{PKC} \alpha$, an isoform thought to play a crucial role in the normal regulation of cell growth (Asaoka et al, 1992).

In summary, the experimental evidence obtained in the current study is consistent with $\mathrm{DAG} \rightarrow \mathrm{PKC} \alpha \rightarrow c-$ myc/max acting as the intracellular signal-transduction pathway mediating PRL stimulation of hepatic ODC activity in vivo. More importantly, our results demonstrate that nurturing touch acts at a target point in this signaling conduit, that is, the activation of $\mathrm{PKC} \alpha$ by $\mathrm{DAG}$, to regulate tissue ODC responsiveness to trophic hormones and thereby growth and development of the neonate.

\section{ACKNOWLEDGMENTS}

This research was partially supported by USF Grant IBN-0090769. VF Ingledue was a recipient of a Howard Hughes Medical Institute Research Fellow.

\section{REFERENCES}

Alessenko A, Khan WA, Wetsel WC, Hannun YA (1992). Selective changes in protein kinase $\mathrm{C}$ isoenzymes in rat liver nuclei during liver regeneration. Biochem Biophys Res Comm 182: 1333-1339.

Asaoka Y, Nakamura S, Yoshida K, Nishizuka Y (1992). Protein kinase $\mathrm{C}$, calcium and phospholipid degradation. Trends Biochem Sci 17: 414-417.

Bartolome JV, Wang S, Bartolome MB (1995). Transcriptiondependent and -independent regulation of hepatic ornithine decarboxylase activity by CNS $\beta$-endorphin in rat pups. $\mathrm{Mol}$ Brain Res 33: 149-156.

Bello-Fernandez C, Packham G, Cleveland JL (1993). The ornithine decarboxylase gene is a transcriptional target of c-myc. Proc Natl Acad Sci USA 90: 7804-7808.

Buckley AR, Buckley DJ (1991). Prolactin stimulated ornithine decarboxylase induction in rat hepatocytes: coupling to diacylglycerol generation and protein kinase C. Life Sci 48: 237-243.

Butler SR, Suskind MR, Schanberg SM (1978). Maternal behavior as regulator of polyamine biosynthesis in brain and heart of the developing rat pup. Science 199: 445-447.

Chomczynski P, Sacchi N (1987). Single step method of RNA isolation by acid guanidium thiocyanate-phenol-chloroform extraction. Anal Biochem 162: 156-159.

Evoniuk GE, Kuhn CM, Schanberg SM (1979). The effect of tactile stimulation on serum growth hormone and tissue ornithine decarboxylase activity during maternal deprivation in rat pups. Comm Psychopharmacol 3: 363-370.

Field T, Grizzle N, Scafidi F, Abrams S, Richardson S, Kuhn C et al (1996). Massage therapy for infants of depressed mothers. Infant Behav Dev 19: 107-112.

Field TM, Schanberg SM, Scafidi F, Bauer CR, Vega-Lahr M, Garcia $\mathrm{R}$ et al (1986). Tactile/kinesthetic stimulation effects on pre-term neonates. Pediatrics 77: 654-658.
Frasier SD, Rallison ML (1972). Growth retardation and emotional deprivation: relative resistance to treatment with human growth hormone. J Pediatrics 80: 603-609.

Greer NL, Bartolome JV, Schanberg SM (1991). Further evidence for the hypothesis that beta-endorphin mediates maternal deprivation effects. Life Sci 48: 643-648.

Heby O (1981). Role of polyamines in the control of cell proliferation and differentiation. Differentiation 19: 1-20.

Jetten AM, Gannong BR, Vandenbark GR, Shirley JE, Bell RM (1985). Role of protein kinase C in diacylglycerol-mediated induction of ornithine decarboxylase and reduction of epidermal growth factor binding. Proc Natl Acad Sci USA 82: 1941 1945.

Kuhn CM, Evoniuk G, Schanberg SM (1979). Loss of tissue sensitivity to growth hormone during maternal deprivation in rats. Life Sci 25: 2089-2097.

Kuhn CM, Schanberg SM, Field T, Symanski R, Zimmermann E, Scafidi $\mathrm{F}$ et al (1991). Tactile-kinesthetic stimulation effects on sympathetic and adrenocortical function in pre-term infants. J Pediatrics 119: 434-440.

Lee JY, Hannun YA, Obeid LM (1996). Ceramide inactivates cellular protein kinase C $\alpha$. J Biol Chem 271: 13169-13174.

Lincoln DW, Hill A, Wakerly JB (1973). The milk ejection reflex of the rat: an intermittent function not abolished by surgical levels of anaesthesia. J Endocrinol 57: 459-476.

Nishizuka Y (1988). The molecular heterogeneity of protein kinase $\mathrm{C}$ and its implications for cellular regulation. Nature 334: 661-665.

Pauk J, Kuhn CM, Field TM, Schanberg SM (1986). Positive effects of tactile versus kinesthetic or vestibular stimulation on neuroendocrine and ODC activity in maternally-deprived rat pups. Life Sci 39: 2081-2087.

Pegg AE, McCann PP (1982). Polyamine metabolism and function. Am J Physiol 243: C212-C221.

Pegg AE, Williams-Ashman HG (1968). Biosynthesis of putrescine in the prostate gland of the rat. Biochem J 100: 533-539.

Peña A, Reddy CD, Wu S, Hickok NJ, Reddy EP, Yumet G et al (1993). Regulation of human ornithine decarboxylase expression by the c-myc.max protein complex. J Biol Chem 25: $27277-$ 27285.

Powell GF, Brasel JA, Blizzard RM (1967a). Emotional deprivation and growth retardation simulating idiopathic hypopituitarism. I. Clinical evaluation of the syndrome. $N$ Engl J Med 276: 12711278.

Powell GF, Brasel JA, Raiti S, Blizzard RM (1967b). Emotional deprivation and growth retardation simulating idiopathic hypopituitarism. II. Endocrinologic evaluation of the syndrome. N Engl J Med 276: 1279-1283.

Rozengurt E, Sinnett-Smith JW (1987). Bombesin induction of c-fos and c-myc proto-oncogenes in swiss 3T3 cells: significance for the mitogenic response. J Cell Physiol 131: 218-225.

Scafidi FA, Field TM, Schanberg SM, Bauer CR, Tucci K, Roberts J et al (1990). Massage stimulates growth in pre-term infants: a replication. Infant Behav Dev 13: 167-188.

Schanberg SM, Evoniuk G, Kuhn CM (1984). Tactile and nutritional aspects of maternal care: specific regulators of neuroendocrine function and cellular development. Proc Soc Exp Biol Med 175: 135-146.

Slotkin TA, Bartolome JV (1986). Role of ornithine decarboxylase and the polyamines in nervous system development: a review. Brain Res Bull 17: 307-320.

Wang S, Bartolome JV, Schanberg SM (1996). Neonatal deprivation of maternal touch may suppress ornithine decarboxylase via downregulation of the proto-oncogenes c-myc and max. $J$ Neurosci 16: 836-842. 